\section{Effects of sampling methods on starch granule size measurement of potato tubers under a light microscope}

\author{
Xiu-Qing Li, ${ }^{1}$ Jichong Zhang, ${ }^{1,2,3}$ \\ Sainan Luo, ${ }^{1}$ Gongshe Liu, ${ }^{3}$ \\ Agnes Murphy, ${ }^{1}$ Yves Leclerc, ${ }^{4}$ Ti Xing $^{5}$ \\ ${ }^{1}$ Potato Research Centre, Agriculture \\ and Agri-Food Canada, Fredericton, \\ New Brunswick, Canada; ${ }^{2}$ Graduate \\ School of the Chinese Academy of \\ Sciences, Beijing, China; ${ }^{3}$ Institute of \\ Botany, Chinese Academy of Sciences, \\ Beijing, China; ${ }^{4}$ McCain Foods Canada \\ Ltd, Florenceville, Canada; ${ }^{5}$ Department \\ of Biology, Carleton University, Ottawa, \\ Ontario, Canada
}

\section{Abstract}

Measurement of starch granules by lightmicroscope is the preferred approach in most laboratories because it is simple, rapid and visual and because both size and shape can be investigated. However, juice from potato tubers consists of starch granules of very different sizes and precipitation/movement speeds which can cause artefacts when sampling the juice and recording microscopic images. In the previously described method, a razor blade was used to scrape and transfer juice from potato tubers directly to a drop of water on a slide for microscopic observation. In this study we used chambers made from tape on microscopic slides to reduce the cover-slip-induced shifting of small and medium granules. We improved the starch measurement reproducibility by testing various juice sampling methods. The reproducibility between repeated experiments using 10 cultivars was increased from a correlation coefficient $r=0.815$ in the razor-blade-scraping method to $r=0.923$ in a squeezing-juice method. The largest starch granule detected was $151 \mu \mathrm{m}$ in length. Sampling methods (using a razor-blade or a garlic press) strongly influenced the granule length values measured from the same potato tuber. The results indicated that 1 ) The squeezing-juice approach is more reproducible, and 2) The average length of starch granules is one of the most reproducible scores but varies according to juice-sampling methods.

\section{Introduction}

Starch in potato tubers consists of granules of very different sizes. ${ }^{1}$ Starch granule size affects starch digestibility properties, ${ }^{2-4}$ food quality such as noodle quality, ${ }^{5}$ and potentially crop productivity. ${ }^{6}$ The rheological behaviour of potato starch dispersions is strongly influenced by granule size. ${ }^{7}$ The larger granule size is closely associated with lower hydrolysis rates in raw starch. ${ }^{3}$ Starch granule sizes also strongly influence the starch recovery from water used for potato processing.

Various approaches to starch granule measurements have been used such as, laser sympatec HELOS particle size analysis, ${ }^{8}$ electrical sensing zone method, ${ }^{9}$ flow cytometer, ${ }^{10}$ and scanning electron microscopy. ${ }^{11,12}$ The simplest method is to scrape some juice from a tuber with a razor blade, transfer it onto a microscope slide, and add a drop of water, and then observe under polarized microscope. ${ }^{13}$ Although small granules may be shifted by the slide cover-slip, this method allows direct observation of starch granules. Examination of starch granules under a microscope is a preferred method because both size and shape can be measured easily. ${ }^{1}$ However, with the light microscope approach, variability can be encountered when sampling juice from potato tubers due to the precipitation rates of different sized granules. While the razor blade scraping method is simple and can target specific portions of the tubers, the reproducibility of the measurement is unknown when the same tubers are measured more than once. In addition, potato tubers are not uniform, and the small amount of materials on the razor blade may or may not represent the whole tuber. Therefore, we tested the use of a juice squeezer to express starch. However, there are also issues associated with this approach: larger granules precipitate much faster than smaller granules during both sampling and spreading the juice on a microscopic slide. In microscopic measurements, differences occur due to the tiny samples and image areas on the microscopic slide. One approach to avoid the starch granule precipitation and sorting issues is to use a microtome to slice histological sections of potato tubers for microscopic measurement. ${ }^{1}$ However, starch granules in histological sections may often be partially embedded in the potato tissues making granule size measurement inaccurate. We compared various starch sampling methods from the same potato tubers, developed a detailed granule length measurement protocol, and compared several ways to analyze granule length data.

\section{Materials and Methods}

\section{Plant materials}

The following ten cultivars of potato (Solanum tuberosum L.) were used to test
Correspondence: Xiu-Qing Li, Potato Research Centre, Potato Research Centre, Agriculture and Agri-Food Canada, 850 Lincoln Road; P.0. Box 20280, Fredericton, New Brunswick, E3B 4Z7, Canada.

E-mail: xiu-qing.li@agr.gc.ca

Key words: starch granule, potato, shape, size.

Acknowledgements: we thank Muhammad Haroon for the general support in the laboratory, Stephen Allaby for assisting us to grow and store the potatoes, and Connie Lee for measuring the starch granule sizes of two cultivars.

Received for publication: 1 February 2011.

Revision received: 20 May 2011.

Accepted for publication: 27 May 2011.

This work is licensed under a Creative Commons Attribution 3.0 License (by-nc 3.0).

(C)Copyright X.-Q. Li et al., 2011

Licensee PAGEPress, Italy

International Journal of Plant Biology 2011; 2:e5 doi:10.4081/pb.2011.e5

reproducibility of the measurement: $\mathrm{AC}$ Novachip, AR2006-02 (F01004), AR2006-07 (F01061), F03007, F03049, Kennebec, Keswick, R.B. West (a Western Canadian sample of Russet Burbank), Rochdale Gold Dorée, and Yukon Gold. Plants were grown at the Potato Research Centre, Agriculture and Agri-Food Canada, Fredericton, in 2008. Harvested tubers of mature size and shape typical of the genotypes were stored at $4^{\circ} \mathrm{C}$ for 6 months and then analyzed for starch granule size. Since the focus of the experiments was to accurately test the technical reproducibility with the same materials, we used one tuber per cultivar in the two experiments (i.e., the two repeats in sampling and measurement of 2008 tubers) to minimize variation caused by sample source.

The following two cultivars were used in an additional experiment to improve starch granule distribution in the microscopic chamber: Red Deer and Yorkton. The plants were grown at the McCain Experimental Farm in New Brunswick in 2009. The tubers were stored at $7^{\circ} \mathrm{C}$ for 4 months. In this experiment, we mixed the pieces of potato flesh from two typical-size tubers per cultivar before using the garlic press to squeeze juice.

\section{Chamber preparation on micro- scopic slides}

Discs, $6 \mathrm{~mm}$ in diameter, were removed from tape (gel sealing tape, Cat\# 11032018, Biometra, Goettingen) using a paper puncher. The tape was then stuck onto a microscope slide. The holes in the tape were used as round chambers to hold potato juices during observation under the microscope. 


\section{Sampling methods}

Three methods with the same microscopic measurement but different sampling approaches were tested. All methods used pieces of tuber removed from the medullar region of the tuber at the approximate middle cross-section to avoid variation of tissue sources between repeats. Method \#1: Potato pieces were squeezed with a garlic press. The resulting juice was collected in a microfuge tube, mixed well, then $3 \mu \mathrm{L}$ was transferred into $7 \mu \mathrm{L}$ water in a round chamber on a slide and mixed with the tip of the pipette immediately. Method \#2: Potato pieces were squeezed with a garlic press; $3 \mu \mathrm{L}$ juice was directly transferred to a round chamber containing 7 $\mu \mathrm{L}$ water and mixed well with the pipette tip immediately. Method \#3: Juice was scraped from a tuber strip with a razor blade and added directly to $7 \mu \mathrm{L}$ water in a round chamber and immediately mixed with the blade. Method \#3 was similar to one used in the literature13 but with the improvement of using tape chambers to avoid small granule shifting. In all methods, the round chambers were covered with a coverslip. During the writing of this paper, a fourth sampling method, modified from Method \#1, was tested to investigate whether it would allow satisfactory distribution of starch granules in the slide chamber. Juice was squeezed into a microfuge tube, mixed well; $20 \mu \mathrm{L}$ juice was immediately transferred to a new microfuge tube containing $70 \mu \mathrm{L}$ water mixed well and $11 \mu \mathrm{L}$ was transferred to a slide chamber for microscopic observation.

\section{Microscopic observation}

Images, from separate areas each with approximately 200 starch granules, were randomly recorded using a Carl Zeiss light microscope with a 20X microscopic objective and equipped with a polarizer and AxioVision Rel 4.7 software (Carl Zeiss). Three images were used to measure starch granules sizes. The starch granules were labelled manually, and the sizes were automatically measured in micrometers using the AxioVision Rel 4.7 software. The data were exported to files compatible with the Microsoft Excel program. In the additional experiment (Method \#4), a lower microscopic objective $(10 \mathrm{X})$ was used to capture a larger image area to facilitate the assessment of the starch granule distribution on microscopic slides.

\section{Data and statistical analysis}

Starch granules are growing organelles with sizes ranging from invisible under light microscope to up to more than 100 micrometers. We tried to measure all the starch granules including the very tiny ones $(8 \mu \mathrm{m})$ as indicated by an arrow in Figure 1A. These tiny granules are nearly invisible under the $10 \mathrm{X}$ or $20 \mathrm{X}$ micro- scope objective and are likely negligible in terms of starch biomass. Therefore, only starch granules with lengths equal to or greater than $8 \mu \mathrm{m}$ were considered measurable for statistical calculations. The mean of starch granule length for each cultivar were calculated. The values from the $10 \%$ largest granules were also used to calculate means. The correlation coefficient of the mean starch granule lengths of the ten cultivars between experiments was used to describe the reproducibility of each sampling/measuring method. The differences, in terms of absolute values, between the mean values obtained from the two experiments were summed and also used to describe the reproducibility of the methods. The method(s) with stronger correlation and smaller differences between the two experiments were considered to have higher reproducibility. A correlation/regression analysis was conducted using the Data Analysis Package of MS Excel 2007. The functions of Summarize by Group
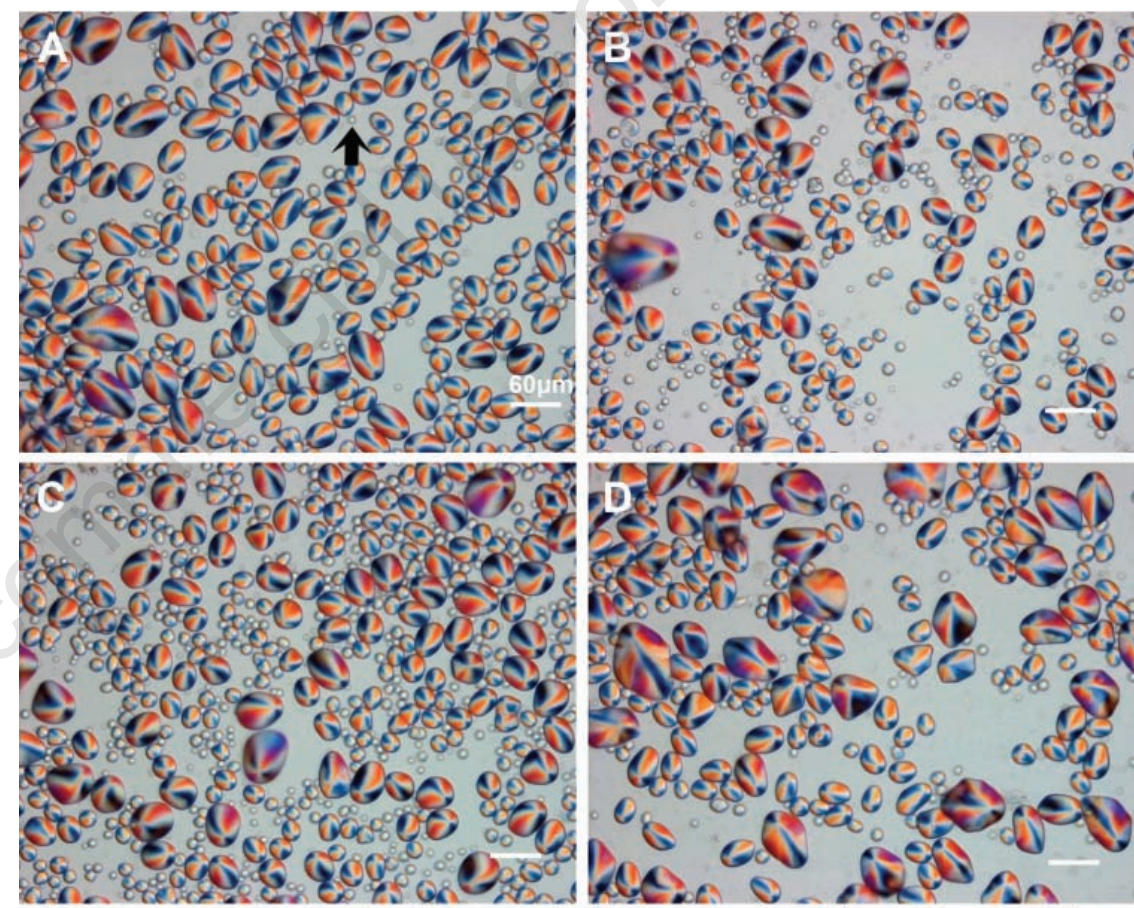

Figure 1. Starch granules of different potato cultivars. Microscopic objective: 20X. (A) AC Novachip; (B) AR2006-02 (F01004); (C) AR2006-07(F01061); (D) F03007; (E) F03049; (F) Kennebec. The small starch granule indicated by an arrow as a tiny spot in Figure 1A had a length of $8.5 \mu \mathrm{m}$. Starch granules larger than $8 \mu \mathrm{m}$ were measured.

and Analysis of Variance (ANOVA) in SAS program (SAS 9.2, Cary, NC, USA) were used to characterize the data and to conduct Duncan's multiple-range tests for mean starch length per cultivar. To avoid the issue of unequal distribution of starch granules between cultivars, we conducted $\log _{2}$ transformation for the starch size values before the ANOVA and Duncan's multiple-range tests.

\section{Results}

\section{Starch granules}

In a pre-test during method development, we found that flat microscopic slides could not be used for this study directly because granules, particularly the smaller and medium ones, moved from one side to the other. This movement caused larger granules to remain where the juice was loaded while smaller gran-
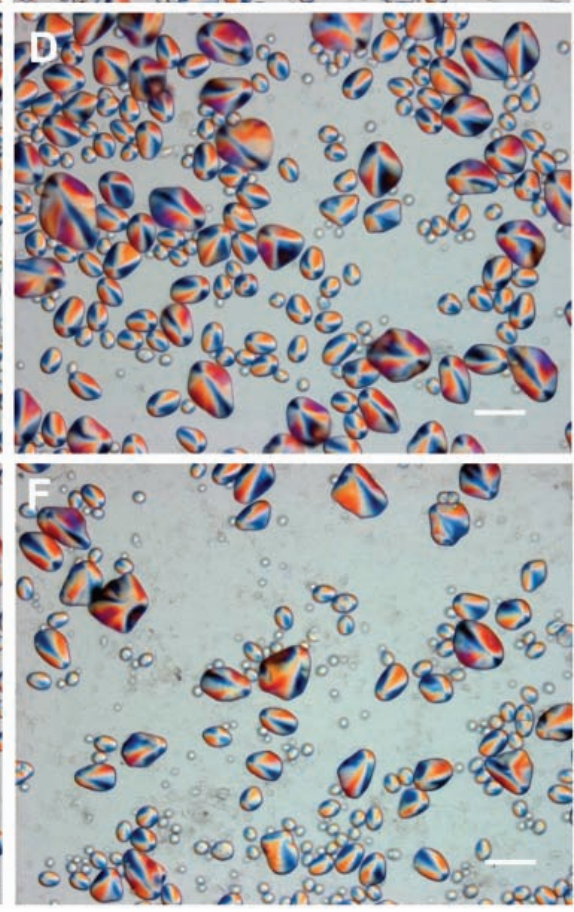

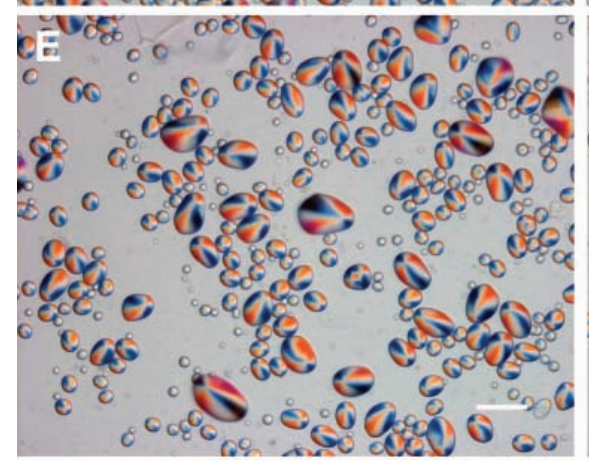

OPEN $\bigcirc$ ACCESS

[International Journal of Plant Biology 2011; 2:e5]

[page 15] 
ules gathered elsewhere (figures not shown). We found that chambers made from tape affixed to the microscopic slides helped considerably to reduce the shifting of small and medium granules and made the measurement of starch granules more representative of the entire granule population (Figures 1 and 2).

Starch granules without staining are colourful under the microscope. Depending on the polarizer adjustment, starch granules can appear smooth (Figures 1 and 2) or show reflections (Figure 3 ). The shape of starch granules also varied between cultivars. Kennebec frequently had large starch granules (Figure 1F) with clearly different shapes from those in other cultivars. AR2006-07(F01061) had both many tiny starch granules and some quite large granules (Figure 1C). Yukon Gold had regular but mainly small starch granules (Figure 2D). The proportions of large and small starch granules were different between cultivars.

The starch granules showed a very large variation in length between granules from the same tuber in the 2008 samples, ranging from a few micrometers to $100 \mu \mathrm{m}$ (Figures 1 and 2). Larger granules were observed in tubers from F03007 (Figure 1D) and AC Novachip (Figure 1A) than from other cultivars. The smallest granules were observed from Yukon Gold (Figure 2D). Compared to the starch granules from other cultivars, granules from Yukon Gold were more regular in shape (Figure 2D). The largest single granules were observed in AR2006-02 (100.11 $\mu \mathrm{m}$, Figure 1B) and R. Gold Dorée $(90.28 \mu \mathrm{m}$, Figure $2 \mathrm{C})$ in the tubers harvested in 2008. The largest starch granule detected in this study was 151 $\mu \mathrm{m}$ in the cultivar Yorkton (Figure 3 ) from the 2009 tubers.

\section{Differences in the mean length of granules obtained from three juice- sampling methods}

In total, 50,530 starch granules measurements (equal to or larger than $8 \mu \mathrm{m}$ ) were used in statistics, with 16,843 granules per method on average. The average length of granules was $23 \mu \mathrm{m}$ from all the 50,530 granules, and $49.26 \mu \mathrm{m}$ for the $10 \%$ largest granules (Table 1). The average length of starch granules was largest in Method \#3, and smallest in Method \#1 (Table 1). The average length of starch granules from Method \#2 was closer to that of Method \#1 (Table 1).

The average length of all the measurable starch granules from the ten cultivars was found to be largest in F03007 $(29.55 \mu \mathrm{m})$ and in AC Novachip $(29.34 \mu \mathrm{m})$, and smallest in Yukon Gold (19.48 $\mu \mathrm{m})$ and AR2006-07 (20.61 $\mu \mathrm{m})$ (Table 2). The average length of the $10 \%$ largest granules was in the same order: the largest was found in tubers of F03007 (60.19
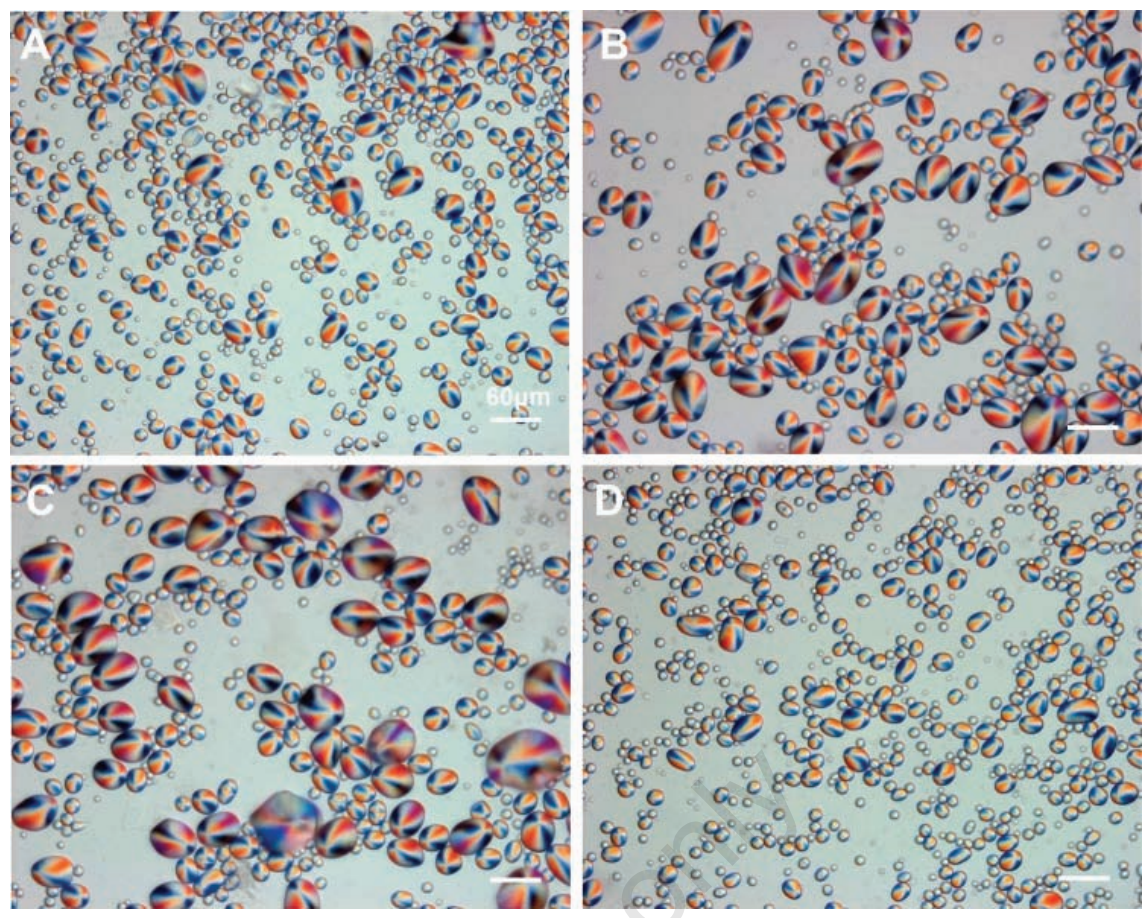

Figure 2. Starch granules of cultivars. Microscopic objective: 20X. (A) Keswick; (B) R.B. West; (C) Rochdale Gold Dorée; (D) Yukon Gold.

Table 1. ANOVA analysis and sampling method comparison for the determination of starch granule size.

\begin{tabular}{lccc} 
Method & $\begin{array}{c}\text { No. } \\
\text { of gramules }\end{array}$ & $\begin{array}{c}\text { Mean length }( \pm \text { StDev) } \\
\text { of all granules }(\mu \mathrm{m})^{\mathrm{x}}\end{array}$ & $\begin{array}{c}\text { Mean length }( \pm \text { StDev) } \\
\text { of 10\% largest granules }(\mu \mathrm{m})^{\mathrm{x}}\end{array}$ \\
Method 1 & 19915 & $22.14 \pm 12.24 \mathrm{C}$ & $46.25 \pm 12.22 \mathrm{C}$ \\
Method 2 & 20154 & $22.38 \pm 12.36 \mathrm{~B}$ & $47.43 \pm 12.06 \mathrm{~B}$ \\
\hline Method 3 & 10461 & $25.94 \pm 15.40 \mathrm{~A}$ & $58.50 \pm 11.96 \mathrm{~A}$ \\
Overall mean & 16843 & $23.03 \pm 13.09$ & $49.26 \pm 13.00$ \\
\hline
\end{tabular}

XValues labelled with the same letter in the same column are not significantly different at the $\mathrm{P}<0.05$ level based on ANOVA and Duncan's multiple-range test after Log2 transformation of the length data. ${ }^{\mathrm{Y}}$ The overall mean is the mean of all the measurable granules, not the mean of the three means listed in the table.

Table 2. ANOVA analysis of starch granule sizes and comparison between cultivars.

\begin{tabular}{lcccc} 
Method & $\begin{array}{c}\text { No. of } \\
\text { granules }\end{array}$ & $\begin{array}{c}\text { Overall mean } \\
( \pm \text { StDev) } \\
(\mu \mathrm{m})^{\mathrm{x}}\end{array}$ & $\begin{array}{c}\text { No. of 10\% } \\
\text { largest } \\
\text { granules }\end{array}$ & $\begin{array}{c}\text { Mean length } \\
( \pm \text { StDev) of 10\% } \\
\text { largest granules } \\
(\text { (1) })^{\mathrm{x}}\end{array}$ \\
\hline F03007 & 3268 & $29.55 \pm 15.69 \mathrm{~A}$ & 327 & $60.19 \pm 9.75 \mathrm{~A}$ \\
AC Novachip & 4030 & $29.34 \pm 15.71 \mathrm{~A}$ & 403 & $60.49 \pm 11.42 \mathrm{~A}$ \\
\hline R.B. West & 5673 & $25.55 \pm 13.93 \mathrm{~B}$ & 568 & $54.63 \pm 11.07 \mathrm{~B}$ \\
AR2006-02 (F01004) & 4612 & $23.51 \pm 12.29 \mathrm{C}$ & 463 & $47.20 \pm 11.86 \mathrm{E}$ \\
\hline Rochdale Gold Dorée & 3852 & $23.50 \pm 13.33 \mathrm{C}$ & 385 & $51.28 \pm 12.96 \mathrm{C}$ \\
Kennebec & 6275 & $21.86 \pm 13.23 \mathrm{D}$ & 629 & $50.25 \pm 12.94 \mathrm{CD}$ \\
\hline F03049 & 4026 & $21.39 \pm 11.59 \mathrm{D}$ & 407 & $46.87 \pm 9.69 \mathrm{E}$ \\
Keswick & 5967 & $20.79 \pm 10.63 \mathrm{D}$ & 597 & $43.13 \pm 11.94 \mathrm{~F}$ \\
\hline AR2006-07 (F01061) & 6756 & $20.61 \pm 12.58 \mathrm{E}$ & 677 & $48.73 \pm 11.62 \mathrm{D}$ \\
Yukon Gold & 6071 & $19.48 \pm 9.08 \mathrm{E}$ & 608 & $38.40 \pm 8.75 \mathrm{G}$
\end{tabular}

XValues labelled with the same letter in the same column are not significantly different at the $\mathrm{P}<0.05$ level based on ANOVA and Duncan's multiple-range test after $\log _{2}$ transformation of the starch granule length data. 
$\mu \mathrm{m})$ and $\mathrm{AC}$ Novachip $(60.49 \mu \mathrm{m})$, and the smallest in Yukon Gold $(38.40 \mu \mathrm{m})$ (Table 2).

\section{Reproducibility in terms of correla- tion coefficients and the sum of absolute difference}

We measured the length of the largest single granule, the $10 \%$ largest granules, the median length of all the measurable granules, and the mean of all the measurable granules in the tuber of each cultivar. Significant correlation was obtained between two experiments for all these length values. The length of the largest single granule showed only a moderate correlation between experiment 1 and experiment 2 in all the three methods tested $(r=0.654,0.888$, and 0.711 , for the Methods \#1, 2, 3, respectively) (Table 3 ). The $10 \%$ of largest starch granules demonstrated a better correlation between the two experiments $(r=0.826,0.849$, and 0.774 , for the Methods \#1, 2, 3, respectively) (Table 3). The median value of length of all the measurable starch granules had strong correlation between repeats in Method \#1 $(r=0.9311)$ compared to Method \#2 $(r=0.868)$ and Method \#3 $(r=0.864)$. The mean value of length for all measurable starch granules showed also very strong overall correlation between the two experiments, with correlation coefficients of $0.923,0.915$, and 0.815 , for Methods \#1, 2, 3, respectively (Table 4). The sum of the absolute difference of starch granule lengths, either all the granules or the $10 \%$ largest, between repeats of the cultivars also indicated that Method \#2 and Method \#1 were the best (Table 4). Hence, Method \#1 and Method \#2, both squeezing-juice approaches, showed an overall stronger correlation or repeatability between the experiments than did Method \#3.

\section{Further improvement of starch granule distribution on microscopic slides}

Even though Methods \#1 and 2 showed very good results as described in the previous paragraphs, there were still non-uniformity issues for starch granule distribution on the microscopic slide sometimes such as shown in Figure 2A. Therefore we added Method \#4 (diluted juice mixed with water in a microfuge tube immediately before loading to slides) to test for granule distribution on slides using two different cultivars available at that time.
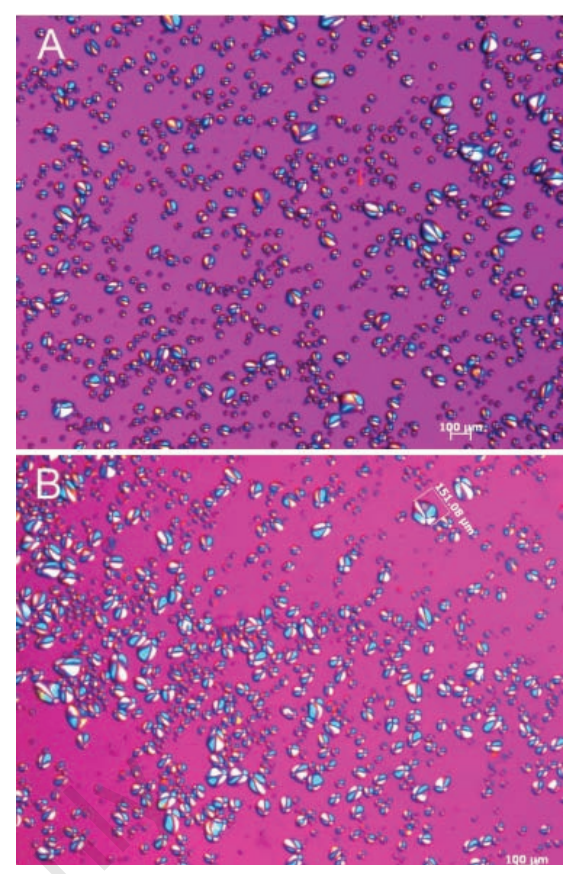

Figure 3. Distribution of starch granules taken from the pre-diluted juice (Method 4), from two potato cultivars. (A) Red Deer; (B) Yorkton. Microscopic objective: 10X.

Table 3. The lengths of the single largest starch granule, the $10 \%$ largest starch granules, the median value of measurable starch granules, and reproducibility between repeated experiments. ${ }^{a}$

\begin{tabular}{|c|c|c|c|c|c|c|c|c|c|}
\hline \multirow[t]{2}{*}{ Method } & \multicolumn{3}{|c|}{ The largest granule } & \multicolumn{3}{|c|}{ The $10 \%$ largest granules } & \multicolumn{3}{|c|}{ Length median (um) } \\
\hline & $\begin{array}{l}\text { Rep 1 } \\
\text { length } \\
(\mu \mathrm{m})\end{array}$ & $\begin{array}{l}\text { Rep } 2 \\
\text { length } \\
(\mu \mathrm{m})\end{array}$ & $\begin{array}{l}\text { Correlation/ } \\
\text { Regression }\end{array}$ & $\begin{array}{l}\text { Rep } 1 \\
\text { length mean } \\
\text { ( } 1 \mathrm{mim})\end{array}$ & $\begin{array}{l}\text { Rep } 2 \\
\text { length mean } \\
(\mu \mathrm{m})\end{array}$ & $\begin{array}{l}\text { Correlation/ } \\
\text { Regression }\end{array}$ & $\begin{array}{c}\text { Rep } 1 \\
\text { length } \\
(\mu \mathrm{m})\end{array}$ & $\begin{array}{c}\text { Rep 2 } \\
\text { length } \\
\text { ( } 1 \mathrm{~m})\end{array}$ & $\begin{array}{l}\text { Correlation/ } \\
\text { Regression }\end{array}$ \\
\hline Method 1 & 70.67 & 70.31 & $\begin{array}{l}r=0.654 \\
r^{2}=0.428 \\
P=0.0403\end{array}$ & 49.12 & 46.95 & $\begin{array}{l}r=0.826 \\
r^{2}=0.683 \\
P=0.0041\end{array}$ & 20.55 & 19.54 & $\begin{array}{l}r=0.9311 \\
r^{2}=0.867 \\
P=0.0001\end{array}$ \\
\hline Method 2 & 74.51 & 71.80 & $\begin{array}{r}r=0.888 \\
r^{2}=0.788 \\
P=0.0006\end{array}$ & 50.59 & 47.87 & $\begin{array}{c}r=0.849 \\
r^{2}=0.721 \\
P=0.0019\end{array}$ & 20.70 & 20.29 & $\begin{array}{c}r=0.868 \\
r^{2}=0.753 \\
P=0.0011\end{array}$ \\
\hline Method 3 & 78.40 & 81.19 & $\begin{array}{c}r=0.711 \\
r^{2}=0.505 \\
P=0.0213\end{array}$ & 59.16 & 60.81 & $\begin{array}{l}r=0.774 \\
r^{2}=0.599 \\
P=0.0086\end{array}$ & 21.82 & 22.82 & $\begin{array}{c}r=0.846 \\
r^{2}=0.716 \\
P=0.0020\end{array}$ \\
\hline
\end{tabular}

aThe data were from 10 potato cultivars: AC Novachip, AR2006-02, AR2006-07, F03007, F03049, Kennebec, Keswick, R.B. West, R. Gold Dorée, and Yukon Gold.

Table 4. Means of all the measurable starch granules and the reproducibility between repeated experiments. ${ }^{a}$

\begin{tabular}{|c|c|c|c|c|c|c|c|}
\hline Method & $\begin{array}{c}\text { Rep } 1 \\
\text { granule } \\
\text { no. }\end{array}$ & $\begin{array}{l}\text { Rep } 1 \\
\text { length } \\
\text { mean } \\
(\mu \mathrm{m})\end{array}$ & $\begin{array}{c}\text { Rep } 2 \\
\text { granule } \\
\text { no. }\end{array}$ & $\begin{array}{l}\text { Rep } 2 \\
\text { length } \\
\text { mean } \\
(\mu \mathrm{m})\end{array}$ & $\begin{array}{c}\text { Abs diff } \\
\text { [Rep1-Rep2] }\end{array}$ & $\begin{array}{c}\text { Total } \\
\text { Reps mean } \\
(\mu \mathrm{m})\end{array}$ & $\begin{array}{c}\text { Correlation/ Regression } \\
\text { Rep1, Rep2 }\end{array}$ \\
\hline
\end{tabular}

\begin{tabular}{|c|c|c|c|c|c|c|c|}
\hline Method 1 & 933 & 23.44 & 1058 & 22.34 & 1.91 & 22.79 & $\begin{array}{l}r=0.923 \\
r^{2}=0.852 \\
P=0.0001\end{array}$ \\
\hline Method 2 & 1019 & 23.72 & 996 & 22.93 & 1.65 & 23.36 & $\begin{aligned} r & =0.915 \\
r^{2} & =0.8378 \\
P & =0.0002\end{aligned}$ \\
\hline Method 3 & 532 & 26.23 & 514 & 26.96 & 2.13 & 26.54 & $\begin{array}{l}r=0.815 \\
r^{2}=0.664 \\
P=0.0041\end{array}$ \\
\hline
\end{tabular}

aThe data were from 10 potato cultivars: AC Novachip, AR2006-02, AR2006-07, F03007, F03049, Kennebec, Keswick, R.B. West, R. Gold Dorée, Yukon Gold. 
Satisfactory distribution of starch granules on the microscopic slide was obtained for both cultivars (Figure 3 ).

Regardless of whether juice was pre-diluted or diluted directly on the slides, we found that it was important to use the juice immediately before it became brown or started to show starch precipitation. It was also important to avoid air bubbles between the slide and the cover-slip. Three or more chambers can be prepared from each potato juice sample at a time to allow the use of only uniform and bubblefree ones for measurement.

\section{Discussion and Conclusion}

The main purpose of this study was to develop and test the reproducibility of several sampling methods to measure starch granules. Therefore, we chose the same tuber approach to ensure that the sample sources for the same cultivar in the two comparative experiments were nearly identical. In this approach, the measured variation in starch size resulted from differences in the methods not from variation between tubers within the same cultivar.

This study did not intend to determine which cultivars have larger starch granules than others or to determine the effect of storage on starch granules. Verification experiments will be required to demonstrate that these cultivars consistently show similar orders of starch granule size as described in this paper. However, the starch granule sizes measures in this study may indeed be representative of the cultivars to some degree because typical, mature size tubers from field - grown plants were used.

This is the first study of starch granule size in these cultivars and differences were recorded. Of the ten cultivars, F03007 and AC Novachip had the largest starch granules; Yukon Gold had the smallest. All three cultivars were released from the potato breeding program of Agriculture and Agri-Food Canada; Yukon Gold was a joint release between Agriculture and Agri-Food Canada, University of Guelph and the Ontario Ministry of Agriculture and Food. F03007 and AC Novachip are processing potato cultivars, while Yukon Gold, with light yellow flesh, is one of the most popular table potato cultivars in Canada and USA. It has also been used to make fresh-cut French fries in restaurants and speciality fry outlets. Yukon Gold was selected from $4 \mathrm{x} \cdot 2 \mathrm{x}$ hybrids. ${ }^{14}$ Further research may be required to investigate whether the smaller starch grain trait is inheritable and whether it is influenced by genes from the diploid potato parent.

Several processing (French fries or chips) cultivars such as F03007, AC Novachip, Russet Burbank, and Yorkton showed large starch granules. Further research is required to verify whether potato clones with large starch granules tend to be selected when breeding cultivars for processing qualities.

Although the length of the largest granule and the average length of the $10 \%$ largest granules showed significant correlation between experiments, the mean value and the median value of the overall measureable starch granules showed the highest reproducibility. The mean value (the average length) of all the measurable starch granules appears to be the best among these measurements because the correlation coefficient between experiments was larger than 0.9 in both Method \#1 and Method \#2 (Table 4).

The average starch granules are larger in Method \#3 (the use of a razor blade to scrape some materials) $)^{13}$ than the granules obtained from the other methods (squeezed juice). It is unclear what caused this difference, but the razor blade tends to collect more large granules than small granules.

In the two juicing methods (Method \#1 and 2), Method \#2 had more larger starch granules than the Method \#1 as indicated by the mean value of the $10 \%$ largest starch granules. It is unclear what caused this difference. We suspect that it was related to the difference in precipitation between large and small granules, because different sized granules precipitate differently. ${ }^{15}$ Method \#2 collected juice from the juice drop beneath the press, and it was likely that the starch distribution in the juice drop was not uniform due to differences in precipitation rates. The lower portion of the drops had apparently accumulated more large granules. The Method \#1 sample was likely better mixed before pipetting the juice to the microscopic slide. We have recently used the Method \#1 to evaluate the starch granule sizes of 14 heritage potato cultivars over two years. The reproducibility of the results between the two years was very high and reached 97\% ( $\left.r=0.9754, r^{2}=0.9513, \mathrm{P}=0.000000003\right)$, even though the weather and environmental conditions were not the same in the two years. The study of heritage cultivars confirmed that Method \#1 is a reproducible, reliable method for the measurement of starch granule sizes in potato tubers. In conclusion, the results indicated the following: i) All the three sampling/microscopic methods tested can give reproducible results in measuring starch granules from potato tubers; ii) Starch granule size measured is very sensitive to the juice sampling method used; iii) The mean value of all measurable starch granules is more reproducible than several other values measured; iv) The juicing methods, either pre-diluted before loading or directly mixed in the slide chamber were found to have better reproducibility than the razor scraping approach.

\section{References}

1. Reeve RM. Suggested improvements for microscopic measurement of cells and starch granules in fresh potatoes. Amer Potato J 1967;44:41-50.

2. Dhital S, Shrestha AK, Gidley MJ. Relationship between granule size and in vitro digestibility of maize and potato starches. Carbohydrate Polym 2010;82:480-8.

3. Noda T, Takigawa S, Matsuura-Endo C, et al. Factors affecting the digestibility of raw and gelatinized potato starches. Food Chem 2008;110:465-70.

4. Parada J, Aguilera JM. In vitro digestibility and glycemic response of potato starch is related to granule size and degree of gelatinization. $\mathrm{J}$ Food Sci 2009;74:E34-8.

5. Chen Z, Schols HA, Voragen AGJ. Starch granule size strongly determines starch noodle processing and noodle quality. J Food Sci 2003;68:1584-9.

6. Hofvander P, Andersson M, Larsson CT, Larsson H. Field performance and starch characteristics of high-amylose potatoes obtained by antisense gene targeting of two branching enzymes. Plant Biotechnol J 2004;2:311-20.

7. Morikawa K, Nishinari K. Effects of granule size and size distribution on rheological behavior of chemically modified potato starch. J Food Sci 2002;67:1388-92.

8. Noda T, Tsuda S, Mori M, et al. The effect of harvest dates on the starch properties of various potato cultivars. Food Chem 2004; 86:11925.

9. Yusuph M, Tester RF, Ansell R, Snape CE. Composition and properties of starches extracted from tubers of different potato varieties grown under the same environmental conditions. Food Chem 2003;82:283-9.

10. O'Donoghue EP, Marangoni AG, Yada RY. The relationship of chip color with structural parameters of starch. Amer Potato J 1996;73:545-58.

11. Kaur L, Singh J, McCarthy OJ, Singh H. Physico-chemical, rheological and structural properties of fractionated potato starches. $\mathrm{J}$ Food Engin 2007;82:383-94.

12. Peshin A. Characterization of starch isolated from potato tubers (Solanum tuberosum L.). J Food Sci Technol 2001;38:447-9.

13. Geigenberger P, Stamme C, Tjaden J, et al. Tuber physiology and properties of starch from tubers of transgenic potato plants with altered plastidic adenylate transporter activity. Plant Physiol 2001;125: 1667-78.

14. Johnston GR, Rowberry RG. Yukon Gold: A new yellow-fleshed, medium-early, high quality table and French-fry cultivar. Amer Potato J 1981;58:241-4.

15. Bryant DC. Apparatus for fractionating mixtures of large and small starch granules. Lab Pract 1973;22:371. 